\title{
THE
}

\section{Latinx Boys and Juvenile Delinquency}

Judy Van Wyk

University of Rhode Island, vellosa@uri.edu

Follow this and additional works at: https://digitalcommons.uri.edu/soc_facpubs

The University of Rhode Island Faculty have made this article openly available.

Please let us know how Open Access to this research benefits you.

This is a pre-publication author manuscript of the final, published article.

Terms of Use

This article is made available under the terms and conditions applicable towards Open Access

Policy Articles, as set forth in our Terms of Use.

\section{Citation/Publisher Attribution}

Van Wyk, J. A. (2020). Latinx Boys and Juvenile Delinquency. Crime \& Delinquency. https://doi.org/ $10.1177 / 0011128720977457$

Available at: https://doi.org/10.1177/0011128720977457

This Article is brought to you for free and open access by the Sociology \& Anthropology at DigitalCommons@URI. It has been accepted for inclusion in Sociology \& Anthropology Faculty Publications by an authorized administrator of DigitalCommons@URI. For more information, please contact digitalcommons-group@uri.edu. 


\title{
Latinx Boys and Juvenile Delinquency
}

\section{Judy A. Van Wyk}

University of Rhode Island, Department of Sociology and Anthropology, 507 Chafee Social Science Center, Kingston, RI 02881 (e-mail: vanwyk@uri.edu).

\begin{abstract}
This study examines Latinx boys in the juvenile justice system and addresses acculturation theory to assess whether or not adjudicated foreign-born Latinx boys are more delinquent than others before adjudication, and whether or not these boys are a bigger burden on the juvenile justice system than others? The present study addresses data and methodological issues that plague the current research using the Ocean Tides Database containing multi-year (1975-2019) cross sectional data for 1,083 adjudicated boys. Multivariate analyses confirm that Latinx immigrant youth who are delinquent pose no greater threats to the American public either before or after adjudication than US-born citizens or other immigrants do. There is minimal support for acculturation theory in explaining behavioral differences between first and second-generation Latinx immigrants.
\end{abstract}

\section{Latinx Boys and Juvenile Delinquency}

This study advances the literature on foreign-born Latinx immigrant boys in the juvenile justice system. Although there are plenty of studies on immigration and crime, fewer studies are on the youthful population, partly because it is a small one. Just 3-5 percent of all children in the United States are immigrants. This pattern remains relatively unchanged since 1994 (Child Trends, 2014), but the second-generation immigrant population is growing and currently represents at least $22 \%$ of U.S. juveniles (Child Trends, 2014). This group includes the children or grandchildren of immigrants. A paucity of research on youthful foreign-born and second-generation immigrants at this time in American history when questions about the impacts of immigration on society abound is problematic. This research fills that gap. There are few databases that are detailed and large enough to make distinctions between ethnic groups by country of origin, ethnicity, and whether the subjects are immigrants, and this research fills that gap as well. It is advantageous to draw methodological distinctions between immigrants and US-born ethnic minorities. If immigrants do not pose undue threats to America or the juvenile justice system, then strengthening antiimmigration efforts against these youth is unfounded. If US-born ethnic minorities are more dangerous, then the focus should instead be on their American experiences, and not on immigration. The current study offers a unique opportunity to advance understanding about Latin American immigrants and whether they constitute a significant threat to the American public, and consequently, whether it makes sense to focus on immigration policies that target this population.

\section{Immigrant Youth Crime}

Federal crime data indicate that patterns of offending for all Hispanics are similar across time to white youth (Hockenberry \& Puzzanchera, 2017). This means there are no differences between whites and Hispanics in the amount of crime they commit or types of crimes. Research does find, however that increases in the size of the immigrant population reduce the rate of crime geographically. Ferraro (2015) analyzes national data to assess the impact of increases in the immigrant population by $150 \%$ or more on crime rates. He finds that as the immigrant population rises, crime decreases. Wadsworth (2010) finds similar results in a time series analysis of changes in the size of the immigrant population from 1990-2000 in large metropolitan areas and their effects on homicide and robbery. Green (2016) examines violent and drug-related crime rates between the overall foreign-born population, Mexican population, undocumented immigrant population, and undocumented Mexican population. He finds that variation in the size of each of these foreign populations between states is not associated with crime rates. Most of these studies find that once the contextual characteristics of a neighborhood/area are held constant, immigration status differences in crime disappear, and there are a lot of studies that support these findings.

Bersani, Longhran, and Piquero (2014) argue that a much smaller body of research examines crime differences at the individual level. These studies suggest that first-generation immigrants in general are less likely than native-born Americans to engage in all forms of crime (see recent research - Ewing, Martinez, \& Rumbaut, 2015; Ghandnoosh \& Rovner, 2017). Katz (2008) examined self-report data from Arizona and found that illegal aliens (90\% of them were Mexican) were less likely to be involved in violence, gangs, or most forms of illegal drugs than US citizens. Finding no differences between the criminal behavior of illegal and legal immigrants, other studies 
have focused on differences in crime between foreign-born and US-born ethnic groups.

Bersani et al. (2014) analyze a sub-sample of first $(n=51)$ and second-generation Mexican youth and find that regardless of social disadvantage, first generation Mexican immigrants are significantly less likely to engage in crime and when they do, their criminal trajectory is shorter than second-generation US-born Mexicans. In their study, assimilation also differed between the two groups whereby first-generation immigrants were less-well assimilated into mainstream American culture than those who were born in the United States. Those who were born to first-generation immigrants were more criminal and more socially acculturated into American Culture, regardless of their levels of social disadvantage.

Researchers explain that differences in criminality between first- and second-generation immigrants are due to variations in acculturation and assimilation into American society (known broadly in the research as the immigration paradox ((Marks, Ejesi, \& Garcia Coll, 2014)). Acculturation is a process of adaptations to life in a new culture, whereas assimilation involves the creation of a common cultural life by sharing history, attitudes, and experiences with the host-group (that group that the new group attempts to join) (Teske \& Nelson, 1975). Acculturation and assimilation are both processes that typify ranges and not dichotomies, but they are not identical processes. Teske \& Nelson (1975) conclude that although they can occur together, they are not interdependent, and they differ in two distinct ways. First, assimilation requires acceptance from the host-group - becoming a member of the community and participating without prejudice. Acculturation does not. Assimilation also requires identification with the host-group, while acculturation does not.

Segmented assimilation and selective acculturation are problematic processes that the children of immigrant's encounter (Portes, Fernandez-Kelly \& Haller, 2009). Assimilation results in the acquisition of successful/gainful employment and quality education. Segmented assimilation identifies exogenous factors that determine the extent to which an out-group (the group that enters the new culture) will assimilate into the hostculture. They include access to human capital such as education and good jobs, the social context of the host culture, meaning how well the new culture receives the group, and the composition of family in the out-group (Portes et al., 2009). If family composition utilizes multiple figures, for example, two parents and extended family, then assimilation into the host culture is more likely to occur. Concomitantly, if the out group is welcomed into the host culture, and they arrive with human capital, then they will assimilate - be able to acquire good jobs, education, and other means of success. Portes et al. (2009) illustrate that Mexican immigrants typically arrive in the USA low on exogenous factors; low levels of human capital, they face bias and discrimination, and are limited in their access to family, often having to leave extended family behind. This results in downward assimilation meaning they are not well assimilated into successful society.

Selective acculturation can occur when the children of immigrants are born into American society (Portes et al., 2009). It is a process whereby they reject their parent's culture to acculturate into the host culture. This process erodes communication between children and their parents and reduces parental control and authority. The children of immigrants who experience selective acculturation and downward assimilation are more likely to associate with others who have similar experiences whether or not these associates are immigrant groups - those people who have not been able to assimilate well into their own mainstream culture; people who are more likely to engage in criminal behaviors. These theories suggest then that aspects of American culture, such as economics, education, and interpersonal family relationships, and discrimination are to blame for criminal behavior, not immigration. Poorer conditions lead people toward crime, not just immigrants. This body of research proposes that acculturation into U.S. society increases criminal involvement such that children born in the United States to immigrants engage in greater delinquent behavior than their parents did.

\section{Methodological and Data-Related Issues}

Most of the research on immigrant offending suffers from methodological or data-related concerns that lie outside of the control of researchers. Some limitations are artifacts of population demographics - a relatively low number of immigrants from each group. Just $14 \%$ of the US population are first generation immigrants (American Immigration Council, 2020). The institutions that process immigrants and juveniles often have poor record-keeping too. Only a handful of studies specifically examine the Latinx experience in prison in the United States (LantiguaWilliams, 2016). In fact, only Alaska records Latinx data in the criminal justice system that is publicly accessible (Eppler-Epstein, 2016), and no public access to this information for juveniles in the justice system is available. Categorizations and definitions vary for Latinxs and other immigrants which create issues for explaining withingroup variations (Martinez \& Lee, 2000). If there is greater variability in behavior within an ethnic group than there is between different ethnic groups, then the later differences are less important.

Most research also either lumps all immigrants into a single category or categorizes all Hispanics into a single group regardless of origin. For example, Jennings, Zgoba, Piquero, \& Reingle (2013) randomly select 375 
incarcerated Hispanic adults and examine criminal trajectories across time. They find that foreign born Hispanics experience initial low rate offending, but it intensifies across time. Just $1 \%$ of their sample may be considered as non-Latinx but it creates questions about within-group variation, especially in the current political climate of antiimmigration and anti-science. The database for the current research offers a great deal of detail about ethnicity and country of origin so distinctive categories can be constructed. One reason this is possible is because there is a comparatively large proportion of Latinx delinquent boys in this database. All other such studies focus on Hispanic as a broad category and they report that ethnicity/origin categories are combined to resolve the numbers-problem. The current study reaches the same sample size for Latinx immigrants as most other students that lump all Hispanics together.

Many studies do not distinguish between immigrants and the children of immigrants which obscures acculturation effects. Since immigrants are generally missing altogether from large population and self-report studies on crime, comparatively little is known about offending (Bersani et al., 2014). Furthermore, lumping all firstgeneration immigrants into one category obscures cultural differences. For example, a large national study of youths found that immigrants 15-17 years old were less likely to engage in some youthful transgressions than their nonimmigrant counterparts (Salas-Wright, Vaughn, Schwartz, \& Cordova, 2016). The study analyzes data from a large national sample of multi-year (2002-2009) cross sectional data. Two groups are identified; U.S.-born and all other immigrant youth, and although Hispanic youth were included in the study, the researchers were unable to perform analyses that would allow them to further control for the effects of ethnicity.

Furthermore, there is an over-reliance on incarceration and arrest statistics (Vaughn, Sales-Wright, DeLisi, \& Maynard, 2014), and on self-reports of criminal involvement in this body of literature (Salas-Wright et al., 2016). The former may be problematic since Latinx youth are at greatest risk to be adjudicated delinquent regardless of their levels of criminal engagement (Hockenberry, \& Puzzanchera, 2017). In the current study, the information is cross-checked for accuracy against multiple sources about the boys (social workers, police, teachers, home visits, clinical reports, interviews with parents, and interviews with the boys). The data is not subject to social desirability in the way that only self-reports are. Bias in policing and in the juvenile justice complex more generally, means that arrest data may not adequately reflect involvement in crime.

In general, although the empirical information that we do have consistently indicates that immigrants are not a serious criminal threat to American Society, the consensus among researchers is that there is a general lack of good data to fully assess the issue (Camarota, \& Vaughan, 2009). In the current climate of fear in the United States, these methodological weaknesses are being exploited to push a xenophobic political agenda. A vast body of research consistently finds that immigrant populations living in the United States do not pose criminal threat to Americans, but methodological weaknesses and data inconsistencies introduce doubt about the patterns that emerge. The current study aims to resolve some of these issues.

\section{Research Methods}

This research tests two broad questions; (1) Were adjudicated Latinx immigrant boys more delinquent than others before their adjudications, and were US-born Latinx boys more delinquent than Latinx immigrants; and (2) Are Latinx immigrant delinquent boys a bigger problem while they are in custody in the American juvenile justice system than others, and are US-born Latinx immigrants a bigger problem while they are in custody than Latinx immigrants? The research questions are assessed on the Ocean Tides database. Data construction is fully described in Grebstein, \& Van Wyk (2016). The full database includes information on 2,053 court adjudicated boys who entered the Ocean Tides program to serve 3-12-month terms from 1975 through the first half of 2015. The current analysis includes 1,803 of those cases since $12.2 \%$ of the sample (250) was missing information about either immigration status, ethnicity, or country of origin.

Ocean Tides is a fully accredited school and residential facility. Boys are sentenced to serve on further order of the court (FOC) from the Rhode Island Training School (RITS), the youth prison in Rhode Island. Court officials, in conjunction with Ocean Tides staff make the decision to place boys at Ocean Tides. It is a non-locked facility that includes an in-house school, vocational, and rehabilitation programs. Most residents are ages 13-17. They are supervised on weekdays and on home placement for the weekends. Some boys remain at the facility on weekends under supervision. Boys who are cooperative in the program typically serve a reduced sentence, and those who are very uncooperative or who pose a hazard to themselves or to others are returned to the RITS to serve their full sentence.

\section{Main Variables (Ethnicity/Origin)}

There are four main independent variables: UBNL= U.S.-born, non-Latinx (a proxy measure of acculturation), $\mathrm{IL}=$ immigrant Latinx, UBL $=$ US-born Latinx, and OTH = non- Latinx immigrants. Descriptive 
statistics are presented in Table 1. Included in the U.S.-born, non-Latinx variable are 82 Portuguese boys (A 1976 Act of U.S. Congress deemed Portuguese as non-Hispanic). The second variable is Latinx immigrants (4.2\% of the sample, $\mathrm{n}=86$ ). Whether or not the boys are in the United States legally is indistinguishable in this database. This study includes thirty-eight Puerto Rican-born boys coded as Latinx immigrants even though they hail from a U.S. Territory because their cultural experiences that contribute to acculturation and assimilation processes are more like immigrants on the mainland than non-immigrants. It is customary in this kind of research to include Puerto Rican's as immigrants (see Hirschman, 2001; Bersani et al., 2014). Another 48 immigrants are identified simply as "South American" in the database and are included in this variable. For representative comparison, in $2010,34 \%$ of the Ocean Tides population was Hispanic and 32\% of the boys who remained at the RITS that year were Hispanic. Making these calculations for other years reveals similar results. It appears then that Ocean Tides and the RITS maintain similar population distributions for Hispanic boys. The third variable is US-born Latinx. These boys' biological parents claimed as their heritage; Mexico, Puerto Rico, and the Dominican Republic, but the boys were born on the mainland of United States. The fourth variable is non-Latinx immigrants. Half of them hail from Portugal and Cape Verde. The other half are from Lao, Cambodia, Germany, Africa, and some are simply identified in the original data sources as "Asian immigrants."

\section{Table 1 about here}

\section{Dependent Variables}

Lifetime adjudicated offences are recorded in the database for each boy for each type of offence, but the present study does not contain enough cases of immigrant Latinx or other immigrants to examine differences between each type of crime and so a single variable distinguishes between violent and non-violent crimes. Almost $53 \%$ of the sample had been adjudicated for violent behavior in their lifetime. Considering information from all sources in the database, $63.8 \%$ of the sample had committed at least one violent act that was serious enough for information about it to be included in their file, regardless of whether or not they were officially charged for it. This second variable that more accurately identifies violent behavior is analyzed in this study.

The variable called "other delinquency" includes aggression, being antagonistic, excessive swearing, being disrespectful, fighting with peers, losing control, encountering problems with authority figures, running away, stealing, and truancy. These behaviors combined into an index produce an alpha score of .655 and a range from 8-32 (each concept was originally measured as 1 slight problem, 2 moderate problem, and 3 severe problems - ones that interfere with functioning and/or responsibilities). They were recoded to include boys who had no problem at all with the behaviors. Higher scores on this variable indicate worse behavior. Sixty-eight percent of the Ocean Tides boys were recidivists having experienced at least one prior arrest before their most recent adjudication. There were 255 confirmed gang members in the sample. Well over half of the sample were regularly involved with guns (55.4\%). Alcohol, marijuana use and other drug use are scaled from low use to more intense use. Academic success is also scaled from low to high.

Several variables describe the boys' behaviors after adjudication, while they were residents at Ocean Tides. Violent behavior at Ocean Tides is constructed from all sources in the database in the same way that violent behavior before adjudication is measured. Other delinquency at Ocean Tides includes being antagonistic, excessive swearing, disrespect, fights with peers, being out of control, problems with authority, running away, stealing, truancy, being angry, uncooperative, obnoxious, unpleasant, and rude. These behaviors combined into an index produce an alpha score of .962 and a range from 14-50 (each concept was originally measured as $1=$ slight problem, $2=$ moderate problem, and $3=$ severe problems - ones that interfere with functioning and/or responsibilities). They were recoded to include boys who had no problem at all with the behaviors. Higher scores indicate worse behaviors. Some of the residents incur additional official charges while in custody "New charges" is a dichotomous variable ( $1=$ no new charge, $2=$ new charge). Trouble with peers only considers relationships within the facility, and higher scores indicate worse problems. Alcohol use, marijuana use, other drug use, and academic success as residents of the program are measured in the same way as these behaviors are measured before adjudication. The exit variable indicates how they left the program, either successfully or by being returned to the Rhode Island Training School. Missing cases for this variable $(n=103,5.7 \%)$ include boys whose parents moved them out of state or who were transferred to other kinds of facilities such as mental health facilities.

\section{Control Variables}

Having a family member who has been incarcerated is one of the most influential variables for the prediction of individual criminal or delinquent behavior. Nearly $25 \%$ of the prison population has a sibling who is also criminally involved (Hederos Eriksson, Hjalmarsson, Lindquiest, \& Sandberg, 2016). Family crime is a 
dichotomous variable. In the total sample, almost $40 \%$ of the boys have at least one immediate family member who either had been previously incarcerated or was in prison at the time of the boy's proximate arrest. Socioeconomic status (SES) is included in this study because immigrants, particularly Latinx immigrants are much more likely to experience economic hardship than are most non-immigrants (Painter \& Qian, 2016). It is measured by six categories ranging from poorest to wealthiest. Age is included because it is reasonable to assume that older teens will have had more opportunities than younger ones to engage in delinquent behaviors. It is measured in whole years at the time they were sentenced. Race is measured as $1=$ white (Hispanic-white and white) and 2=non-white (Asian \& Indian, Black \& African American, Cape Verdean, Hispanic non-white, and Native American).

No race is recorded for $13.2 \%$ of the sample $(n=272)$, and SES is missing for $9.3 \%$ of the sample. Race is an important variable to include in this study because research findings on the association between race and delinquency are mixed. Piquero \& Brame (2008, p.391) study serious violent offenders and find support for the "differential criminal justice system selection hypothesis," which explains that due to increased police surveillance of Black youth, their crimes are more likely than others to be detected; Blacks are more likely to be arrested, convicted, and incarcerated. Ridout (1991) explains that the best way to identify patterns in missing information across other variables is by creating dichotomous dummy test variables from the ones that are missing data such that $0=$ non-missing cases and $1=$ missing cases for each of the variables of concern. Then, using each test variable as the dependent variable in turn, calculate backwards conditional logistic regression models containing the theoretical and control variables. Results in the final steps indicate that data for the race variable tend to be missing for boys who are not gang involved $-1.512, \mathrm{p}=.016)$, and who have fewer problems with peer relationships at Ocean Tides (-.706, $\mathrm{p}=.003)$. Data for SES tend to be missing for those who have a less serious problem with prior marijuana use $(\mathrm{B}=-$ $.175, \mathrm{p}=.030$ ), and who do have more serious problems with other drug use as residents of Ocean Tides (.489, $\mathrm{p}=.001)$. There were no other significant correlations with the test variables. Since the relationships that do exist are weak and all but one indicates that data is not missing for the concepts of interest (such as gang or gun involved youth, or boys who are more delinquent than others, it is unlikely that the missing data seriously effects the outcome of this study.

\section{Analyses}

Since both research questions measure differences between social categories, it is important to determine whether the sample is diverse in the first place. This question assesses whether only one-kind of boy is selected to serve his sentence at Ocean Tides instead of at the Training School regardless of ethnicity or place of origin. If so, then it is possible that regardless of ethnicity/origin, the boys would be similar on behavioral characteristics. To test this assumption, Levene's tests of homogeneity of variance for each of the dependent variables that are not dichotomous are calculated and results are presented in Table 2. It would not make sense to use Levene's test for dichotomous variables because if cases were split between the two options equally, it would produce a high probability level, meaning low variance. For example, $63.8 \%$ of the sample had engaged in violent behavior before going to Ocean Tides, and the Levene's test result is 1.968 ( $\mathrm{p}=.117$ ). There is insufficient variance because the split between the presence and the absence of violence is too close to 50/50. That means that the sample is more, not less diverse. The test is useful though to test variance across more than two categories. To interpret the Levene's test, probability values of less than .05 indicate that there is variance - that cases vary on that characteristic. Results indicate that before the boys were sentenced, their behaviors were significantly varied for delinquent behaviors, alcohol use, other drug use, academic success and socioeconomic status (this last one remains the same even at Ocean tides because it is a measure of family SES). Before Ocean Tides, the boys used marijuana to a similar extent. That is the only similarity we find in the sample for these characteristics. These results indicate that the boys on FOC to Ocean Tides are more different from one another than they are similar to one another - they are not all the same kind of boys.

Table 2 about here-

Once the boys are in the Ocean Tides program, we would hope that some of the characteristics change because its purpose is rehabilitation, and they do change. Variance on delinquent behaviors diminish as does alcohol use and variance on academic success. Even at Ocean Tides, however, we see significant differences across ethnic/origin groups in their peer relationships and other drug use. Based on the Levene's tests, it does not appear that the Ocean Tides boys represent one-kind of boy, but instead, they are a diverse group in terms of behavior.

Dependent variables are ones that may either lead to judiciable delinquency or already are, and include behaviors such as violence and other delinquency, poor academic achievement, recidivism, drug and alcohol use, gang involvement and gun use. Other variables include family characteristics such as socioeconomic status and 
incarceration of a family member. These correlates are assessed to address the first research question: are delinquent immigrant Latinx boys more troublesome than other delinquent boys before they are adjudicated? Examining this question will also reveal whether acculturated boys (US-born Latinxs) are more delinquent than Latinx immigrants. For the second question, are Latinx immigrant boys a bigger problem while they are in custody in the juvenile justice system than others, peer relationships are included, new charges, and successful completion of their FOC at Ocean Tides. Bivariate Pearson's coefficients were calculated for all correlations.

\section{Before they are Adjudicated}

To explore the first research question, bivariate analyses indicate that four of the outcome variables do not correlate with any of the four ethnic/origin variables (academic success, other drug use, alcohol use, or violence). These findings are not surprising and are consistent with previous literature. Inconsistent with previous research are correlations with the five remaining variables - ethnicity: recidivism, gang and gun involvement, levels of other delinquency and marijuana use. Therefore, five multivariate models are required for further testing (see Table 3). Independent variables in these models include the four ethnic/origin types: UBNL (US-born non-Latinx), IL (immigrant Latinx), UBL (US-born Latinx) and OTH (all other first-generation immigrants). Included as controls are race, family member's incarceration, age, and socioeconomic status.

\section{Table 3 about here-}

Four of the five models indicate no correlation between the ethnic/origin and outcome variables while controlling for other pertinent variables. Model 2 is weakly associated with gang involvement and in the opposite direction, meaning that each group except for US-born Latinx's is less likely than those who are not in those categories to be involved in gangs while controlling for other characteristics. The correlation between US-born Latinx's and gang involvement is positive, but it is not significant. These findings are important for addressing the acculturation theory that explains why US-born Latinx boys may be more delinquent than immigrant Latinx boys.

To examine this finding further, an ANOVA is calculated (not shown in tables) using a single variable that is constructed of the four ethnic/origin categories. This variable has a non-normal variance and unequal sample size, which can create a statistical error referred to as the Behrens-Fisher Problem (Shingala \& Rajyaguru, 2015). Since comparisons are made pairwise, when a variable includes more than two categories, information about all possible combinations may be difficult to assess, and interpretation of the F-statistic can result in a Type 1 error - a false positive finding. In this case, there can be a significant difference between means for only one of the six possible pairings, and the F-statistic alone does not indicate which one. For that information, Chi-square is best, but that too can result in a Type 1 error. Shingala \& Rajyagura (2015) suggest four post hoc tests to assess the presence of a Type 1 error using categorical variables. Based on the parameters of the main variable in this analysis, the Dunnet $\mathrm{C}$ post hoc test is most appropriate. This test essentially provides a goodness of fit test for each pairing of categories. Chi-square analysis cannot provide this kind of detailed information. In laymen's terms, this procedure more precisely identifies between group variation in the outcome variables by ethnic/origin, albeit without the presence of controls. If a correlation is statistically significant, the Dunnet $\mathrm{C}$ post hoc test identifies which groups differ from one another. Post hoc results identify only one significant correlation between groups - US-born Latinxs are more likely to be involved in gangs than US-born non-Latinx boys (mean difference $=-.141$ ). This finding clarifies what is found in Model 2. Once controls are included in the multivariate analysis, this correlation is no longer significant.

Race significantly predicts gang and gun involvement, and other delinquency. Non-whites are more likely to be involved with gangs and guns, but whites engage in greater other forms of delinquency than non-whites do. Recall that this variable does not include drug use or violent behaviors as these variables were not correlated with any of the ethnic/origin variables at the bivariate level. Boys who have had incarcerated family members are at increased risk of recidivism, other forms of delinquency and marijuana use. Age is associated with three of the outcomes. Older boys are more likely to be recidivists, and use more marijuana than younger boys, and younger ones engage in a greater amount of other forms of delinquency, which makes sense because these behaviors are nonviolent/less serous. Low SES predicts gang involvement, while higher SES increases the use of marijuana.

\section{After they are Adjudicated}

The second research question is whether Latinx immigrant delinquents are more problematic while in juvenile custody than others, and whether acculturation creates differences between US-born and immigrant Latinxs. Five of the outcome variables are not correlated with the ethnic/origin variables in the bivariate correlations and further analyses show no changes in the presence of controls. Table 4 includes four models that include only those outcomes that are significantly correlated to the variables of interest at the bivariate level - other delinquency, 
academic success, other drugs, and alcohol use while the boys were residents in the Ocean Tides program. Included as controls are race, age, SES and other prior delinquent behaviors. One of the best-known correlates of future behavior is past behavior and so, for example, past academic success is included as a predictor of current academic success.

None of the ethnic-origin variables are correlated with the outcomes in the presence of controls. Again, race produces significant findings. Non-whites engage in a greater amount of other forms of delinquency and suffer from lower academic successes. Whites engage in greater use of other drugs than non-whites do. Family imprisonment lowers academic success at Ocean Tides and increases alcohol use. Younger boys engage in greater other forms of delinquency, use of other drugs and alcohol, while older boys perform better than younger ones academically. For all four outcome variables, prior behavior of the same type is a good predictor of their behavior at Ocean Tides.

\section{Discussion}

The first research question is whether adjudicated Latinx immigrant boys are more delinquent than others before adjudication, and if acculturation results in differences between US-born and immigrant Latinxs. Consistent with previous research, analyses across several key variables for the four ethnicity/origin groups find that immigrant Latinx boys are not a significant majority for any misbehavior (violence, other delinquent behaviors, recidivism, alcohol and other drug use, gang or gun involvement, poor academic success, or criminal family members). This finding is particularly interesting since they experience significantly lower SES than any other group in the analyses. Dunnet $\mathrm{C}$ post hoc analysis indicates that immigrant Latinxs experience significantly lower SES than US-born nonLatinxs (mean difference $=-.747$ ), non-Latinx immigrants (-.594), and U.S.-born non-Latinxs (-.461).

Testing the second half of the first research question, multivariate and post hoc analysis reveal that minor differences in gang involvement are found between US-born Latinx and US-born non Latinx boys. Since lower SES increases gang involvement, and US-born Latinx's experience lower SES than non-Latinxs, this finding appears to indicate downward assimilation and segmented acculturation for Latinx born in the United States. Secondgeneration (or later) Latinx youth may seek solidarity by gang involvement as they lose interest in the lifestyles of their immigrant parents.

The second research question is whether Latinx immigrant delinquent boys are more troublesome than others while in official custody, and if acculturation of Latinx populations results in increased delinquency during incarceration. Results do not confirm either of these research questions. Considering other research on the criminality of immigrant populations, it is not surprising that this study finds that Latinx immigrants are not more problematic/delinquent than others. There are two reasons why these results do not support acculturation theory. One is that Ocean Tides may serve as an equalizer for the boys in the program that counter the effects of segmented acculturation that they experienced prior to detention. Another reason is that ethnicity/place of origin may not serve as a valid proxy for assimilation or acculturation.

One interesting caveat of research on immigration and crime that is often ignored is consideration that the presence of criminal immigrants in the country may add to the juvenile justice burden on the American population, meaning that if they were not in the United States, then the American justice system would serve slightly fewer delinquents. However, in most studies on juvenile delinquents that do identify origin of birth, they represent only from 3 to $7 \%$ of the entire sample, and those numbers typically include immigrants from all nations. Since all Latinx, adults included, currently constitute about $13 \%$ of the U.S. population, relatively few of them end up in the juvenile justice system. Also, if for some forms of delinquency, Latinx immigrants engage in less delinquency than their US-born non Latinx peers, then they may serve as positive influences on them, decreasing overall rates of delinquency. Of course, that test is beyond the scope of the present research. Nonetheless, this research suggests that directing legal and social policies toward preventing Latinx youth or their parents from entering this country may not be economically feasible or empirically justifiable.

\section{Study Limitations}

The current study only includes delinquent boys and no girls. It is possible results may differ for girls. The Ocean Tides program only allows male residents, and there is no comparable FOC placement for delinquent girls in Rhode Island. One constant in all research on juvenile offending is that boys commit close to $90 \%$ of all juvenile offences combined, and when they are delinquent, they are much more likely to be processed through the juvenile justice system instead of being deferred for other kinds of treatments. "There is no basic attribute other than a person's sex or gender that divides the population so nearly equal yet shows such an overwhelmingly disproportionate relationship to delinquent and criminal behavior" (Tracy, Kempf-Leonard, \& Abramoske-James, 2009 p. 172). Girls, and the crimes that they commit are important to study, but given the relatively low number of 
cases of female crimes when studying a small sample of delinquents to begin with when a sample is limited to immigrants or further limited to Latinx immigrants, the number of female subjects all but disappears. This may be why so few studies on Latinx or even on the larger category of Hispanics and crime rarely include females. The whole point of including males and females (and for that matter, all other genders) in a study would be to discern differences between gender groups. At this point in time, I am unaware of a Latinx sample of delinquents that includes enough females to make its study informative about gender differences. To date, most studies on this topic include only males.

Another limitation to the study is that Ocean Tides is not a typical youth prison, although its population is very similar to the RITS by race, ethnicity, and crimes committed, it is a residential non-locked facility in which boys are in house and constantly supervised Monday - Friday and at home on weekends. It is not an alternative program either. It simply is not structured the same way as traditional youth prisons or as an alternative to adjudication. For representative comparison, in 2010, there were 894 boys in Rhode Island who were sentenced to the Rhode Island Training School (RI Kids Count, 2018), 303 of them were Hispanic (the Kids Count data does not identify origin of birth or whether they are immigrants). Twenty of the Hispanic boys were sent to Ocean Tides that year along with 39 other boys. So, 34\% of the Ocean Tides population that year was Hispanic and $32 \%$ of the boys who remained at the RITS that year were Hispanic. Making these calculations for other years reveals similar results. It appears then that Ocean Tides and the RITS maintain similar population distributions for Hispanic boys.

Comparisons for behavior appear elsewhere this study. There could be components of the Ocean Tides program that minimize differences between ethnic groups that are not present in more traditional youth prisons. Ocean Tides also has the luxury of refusing residents, and so the most hardened delinquents are either not sent there to begin with, or they are returned to the RITS before their sentence is completed. On average, Ocean Tides accepts about half of the RITS boys who are referred to them. Rejections are typically based on administrative reasons (a relative is already there), assaults against placement staff, severe gang involvement, suicidal tendency or non-compliance (not willing to interview). Severe mental health issues would be problematic at Ocean Tides since success in the program is based on a boy's ability to make reasonably rational decisions. Although the Ocean Tides boys do differ significantly from one another in their behaviors, the worst of the worst are not included in this database. Ocean Tides is currently functioning at a maximum ideal capacity of 29 residents. In 2017, there were 399 youth ages 13 18 held at the RITS (Rhode Island Kids Count 2018), and so it is reasonable to think that there is a fair number of boys at the RITS who are very similar to the boys who are placed on FOC and sent to Ocean Tides.

\section{Implications for Practice and Policy}

In closing, the current research indicates that future research efforts should focus on rehabilitation strategies that help all juveniles, regardless of ethnicity or country of origin to thrive. It also suggests that the right kind of residential programming may combat the criminogenic effects of segmented acculturation and downward assimilation by temporarily removing them from the inequities they face in their communities. Nationally, public and political discourse on immigration needs to be separate from discussions about crime and delinquency, as they are not empirically correlated, and likely never have been (Benton-Cohen, 2018). Although the present study is not a national one, results are in line with most other and this study addresses methodological and measurement issues that plague some of these other studies. Finally, public, legal, and political policy should not be driven by moral panics. The best way to combat crime and delinquency and to strengthen the role of research in the development of criminal justice policy and practice is with sound empirical data.

\section{References}

American Immigration Council (2020). Fact Sheet: Immigrants in the United States. Washington, D.C. Retrieved from https://www.americanimmigrationcouncil.org/research/immigrants-in-the-united-states.

Bersani, B. E., Lughran, T. A., \& Piquero. A. R. (2014). Comparing patterns and predictors of immigrant offending among a sample of adjudicated youth. Journal of Youth Adolescence, 43, 1914-1933.

Camarota, S. A. and Vaughan, J. M. (2009). Immigration and crime: Assessing a conflicted issue. Center for Immigration Studies, Retrieved from cis.org/Report/Immigration-and-Crime.

Child Trends. (2014). Immigrant children: Indicators of child and youth well-being. Child Trends. Retrieved from childtrends.org/indicators/immigrant-children.

Eppler-Epstein, S., Gurvis, A., \& King, R. (2016). The alarming lack of data on Latinos in the criminal justice system. Urban.org, Retrieved from apps.urban.org/features/latino-criminal-justice-data/.

Ewing, W. A., Martinez, D. E., \& Rumbaut. R. G. (2015). The criminalization of immigration in the United States. Special Report: American Immigration Council, Retrieved from AmericanImmigrationCouncil.org.

Ferraro, V. (2015). Immigration and crime in the new destinations, 2000-2007: A test of the disorganizing effect of 
migration. Journal of Quantitative Criminology, 32, 23-45.

Ghandnoosh, N. \& Rovner, J. (2017). Immigration and public safety. The Sentencing Project: Research and Advocacy for Reform, Retrieved from Sentencingproject.org.

Grebstein, L. C. \& Van Wyk, J. A. (2016). Turning the Tide of Male Juvenile Delinquency: The Ocean Tides Approach, New York, New York, Springer Publishing Company.

Green, D. (2016). The Trump hypothesis: Testing immigrant populations as a determinant of violent and drugrelated crime in the United States. Social Science Quarterly. 97(3), 506-524.

Hederos Eriksson, K., Hjalmarsson, R., Lindquiest, M. J., \& Sandberg, A. (2016). The importance of family background and neighborhood effects as determinants of crime. Journal of Population Economics, 29(1), 219-262.

Hirschman, C. (2001). The educational enrollment of immigrant youth: A test of the segmented-assimilation hypothesis. Demography, 38(3), 317-336. doi:10.1353/dem.2001.0028.

Hockenberry, S. and Puzzanchera, C. (2017). National juvenile court data archive: Juvenile court case records 20052014. National Center for Juvenile Justice, Retrieved from ojjdp.gov/ojstatbb/njcda/pdf/DataSnapshot_LatinoYouth2014.pdf.

Jennings, W. G., Zgoba, K., Piquero, A. R., and Reingle, J. M. (2013). Offending trajectories among native-born and foreign-born Latinos to late middle age. Sociological Inquiry, 83(4), 622-647.

Katz, C. M. (2008). The Connection between Illegal Immigrants and Crime. Tempe, AZ: Center for Violence Prevention and Community Safety, Arizona State University.

Lantigua-Williams, J. (2016). Criminal justice is becoming a Latino issue. The Atlantic, Retrieved from theatlantic.com/politics/archive/2016/09/why-criminal-justice-is-becoming-a-latino-issue/500864/.

Marks, A., D., Ejesi, K., \& Garcia Coll, C. (2014). Understadning the U.S. immigrant paradox in childhood and adolescence. Child Development Perspectives, 8(2), 59-64.

Martinez, R. \& Lee, M. T. (2000). On immigration and crime. Pp. 485-524 in J. Reno, D. Marcus, M. L. Leary, and J. E. Samuels, The Nature of Crime: Continuity and Change. Vol. 1. Office of Justice Programs. National Institute of Justice.

Painter, M. A., \& Qian, Z. (2016). Wealth inequality among immigrants: Consistent racial/ethnic inequality in the United States. Population Research and Policy Review, 35(2), 147-175.

Piquero, A. R., \& Brame, R. W. (2008). Assessing the race-crime and ethnicity-crime relationship in a sample of serious adolescent delinquents. Crime and Delinquency, 54(3), 390-422.

Portes, A., Fernandez-Kelly, P.K, \& Haller, W. (2009). The adaptation of the immigrant second generation in America: A theoretical overview and recent evidence. Journal of Ethnic and Migration Studies, 35(7), 1077-1104.

Rhode Island Kid's Count Factbook. (2018). 2018 Rhode Island Kid's Count, Retrieved from rikidscount.org/Portals/0/Uploads/Documents/Factbook\%202018/2018\%20Factbook.pdf.

Ridout, M. S. (1991). Testing for random dropouts in repeated measurement data. Biometrics, 47(4), 1617-9; discussion 1619-21.

Salas-Wright, C. P., Vaughn, M. G., Schwartz, S. J., and Cordova, D. (2016). An "immigrant paradox" for adolescent externalizing behavior? Evidence from a national sample. Social Psychiatry Psychiatric Epidemiology, 51, 27-37.

Shingala, M.C. \& Rajyagura, A. (2015). Comparison of post hock tests for unequal variance. International Journal of New Technologies in Science and Engineering, 2(5), 22-33.

Teske, R. H. C., Jr. \& Nelson, B. H. (1975). Acculturation and assimilation: A clarification. American EthnologistWiley Online Library. https://doi.org/10.1525/ae.1974.1.2.02a00090

Tracy, P. E., Kempf-Leonard, K., \& Abramoske-James, S. (2009). Gender differences in delinquency and juvenile justice processing: Evidence from National data. Crime \& Delinquency. 55(2), 171-215.

Vaughn, M. G., Salas-Wright, C. P., DeLisi, M., \& Maynard, B. R. (2014). The immigrant paradox: Immigrants are less antisocial than native-born Americans. Social Psychiatry Psychiatric Epidemiology, 49(1), 1129-1137.

Wadsworth, T. (2010). Is immigration responsible for the crime drop? An assessment of the influence of immigration on changes in violent crime between 1990 and 2000. Social Science Quarterly, 91(2), 532553. 
Table 1: Univariate Statistics - All variables

\begin{tabular}{|c|c|c|c|c|}
\hline & Categories, or Range \& Mean & Frequency & Percent, or SD & $\mathrm{N}$ \\
\hline \multirow{4}{*}{ Ethnic/Origin } & 1. UBNL: US-Born Non-Latinx & 1,451 & 70.7 & \\
\hline & 2. IL: Immigrant Latinx & 86 & 4.2 & \\
\hline & 3. UBL: US-Born Latinx & 206 & 10.0 & \\
\hline & 4. OTH: Non-Latinx immigrant & 60 & 2.9 & 1,083 \\
\hline \multicolumn{5}{|l|}{ Before Ocean Tides } \\
\hline \multirow[t]{2}{*}{ Violence } & 1. No violence & 653 & 36.2 & \\
\hline & 2. Yes, violence & 1,150 & 63.8 & 1,083 \\
\hline Other Delinquency & $8-32(\bar{x}=18.40)$ & NA & $\mathrm{SD}=5.301$ & 1,083 \\
\hline \multirow[t]{2}{*}{ Recidivism } & 1. Yes, recidivist & 573 & 31.8 & \\
\hline & 2. No prior adjudications & 1,230 & 68.2 & 1,803 \\
\hline \multirow[t]{2}{*}{ Gang } & 1. No gang involvement & 1,548 & 85.9 & \\
\hline & 2. Yes, gang involvement & 255 & 14.1 & 1,803 \\
\hline \multirow[t]{2}{*}{ Guns } & 1. No guns & 805 & 44.6 & \\
\hline & 2. Yes, guns & 998 & 55.4 & 1,803 \\
\hline \multirow{4}{*}{ Alcohol Use } & 1. No use & 688 & 38.2 & \\
\hline & 2. Light use & 509 & 28.2 & \\
\hline & 3. Moderate use & 389 & 21.6 & \\
\hline & 4. Heavy use & 217 & 12.0 & 1,803 \\
\hline \multirow{4}{*}{ Marijuana Use } & 1. No use & 530 & 29.4 & \\
\hline & 2. Light use & 355 & 19.7 & \\
\hline & 3. Moderate use & 501 & 27.8 & \\
\hline & 4. Heavy use & 417 & 23.1 & 1,803 \\
\hline \multirow{4}{*}{ Other Drug Use } & 1. No use & 1,511 & 83.8 & \\
\hline & 2. Light use & 142 & 7.9 & \\
\hline & 3. Moderate use & 107 & 5.9 & \\
\hline & 4. Heavy use & 43 & 2.4 & 1,803 \\
\hline \multirow[t]{4}{*}{ Academic Success } & 1. Poor $\&$ poor range & 1,370 & 80.4 & \\
\hline & 2. Average & 267 & 15.7 & \\
\hline & 3. Above average & 66 & 3.9 & $\begin{array}{l}1,703 \\
(94.5 \%)\end{array}$ \\
\hline & 1. None & 1,089 & 60.4 & \\
\hline Family member in prison & 2. Incarcerated family member & 714 & 39.6 & 1,803 \\
\hline \multirow[t]{6}{*}{ SES } & 1. Underclass & 391 & 21.7 & \\
\hline & 2. Borderline poverty & 328 & 18.2 & \\
\hline & 3. Lower-middle & 565 & 31.3 & \\
\hline & 4. Middle-range & 345 & 19.1 & \\
\hline & 5. Upper-middle & 41 & 2.3 & \\
\hline & 6. Upper & 6 & 0.3 & $1,676(93 \%)$ \\
\hline \multicolumn{5}{|l|}{ At Ocean Tides } \\
\hline \multirow[t]{2}{*}{ Violence } & 1. No violence & 1,400 & 77.6 & \\
\hline & 2. Yes, violence & 406 & 22.4 & 1,803 \\
\hline Other Delinquency & $14-50(\bar{x}=22.39)$ & NA & $\mathrm{SD}=7.809$ & 1,803 \\
\hline \multirow[t]{2}{*}{ New Charges } & 1. No new charge & 1,393 & 77.3 & \\
\hline & 2. Yes, new charge(s) & 410 & 22.7 & 1,803 \\
\hline \multirow[t]{3}{*}{ Peer Relations } & $\begin{array}{l}\text { 1. gets along with peers very well } \\
\text { all or most of the time }\end{array}$ & 644 & 37.8 & \\
\hline & $\begin{array}{l}\text { 2. gets along well with some peers } \\
\text { and not so well with others or at } \\
\text { least one peer }\end{array}$ & 795 & 46.6 & \\
\hline & $\begin{array}{l}\text { 3. does not get along well with } \\
\text { most of his peers }\end{array}$ & 232 & 13.6 & \\
\hline
\end{tabular}




\begin{tabular}{|c|c|c|c|c|}
\hline & $\begin{array}{l}\text { 4. does not get along with any of } \\
\text { his peers }\end{array}$ & 34 & 2.0 & $\begin{array}{l}1,705 \\
(94.6 \%)\end{array}$ \\
\hline \multirow[t]{4}{*}{ Alcohol Use } & 1. No use & 1,021 & 56.6 & \\
\hline & 2. Light use & 397 & 22.0 & \\
\hline & 3. Moderate use & 287 & 15.9 & \\
\hline & 4. Heavy use & 98 & 5.4 & 1,083 \\
\hline \multirow{4}{*}{ Marijuana Use } & 1. No use & 811 & 45.0 & \\
\hline & 2. Light use & 411 & 22.8 & \\
\hline & 3. Moderate use & 386 & 21.4 & \\
\hline & 4. Heavy use & 195 & 10.8 & 1,083 \\
\hline \multirow{4}{*}{ Other Drug Use } & 1. No use & 1,651 & 91.6 & \\
\hline & 2. Light use & 68 & 3.8 & \\
\hline & 3. Moderate use & 70 & 3.9 & \\
\hline & 4. Heavy use & 14 & 0.8 & 1,803 \\
\hline \multirow[t]{3}{*}{ Academic Success } & 1. Poor \& poor range & 423 & 25.3 & \\
\hline & 2. Average & 780 & 46.7 & \\
\hline & 3. Above average & 468 & 28 & $\begin{array}{l}1,671 \\
(92.7 \%)\end{array}$ \\
\hline \multirow[t]{2}{*}{ Condition of Exit } & 1. Returned to the RITS & 561 & 31.1 & \\
\hline & 2. Successful completion & 1,139 & 63.2 & $\begin{array}{l}1,700 \\
(94.3 \%)\end{array}$ \\
\hline \multirow[t]{2}{*}{ Race } & 1. White & 1,029 & 50.1 & \\
\hline & 2. Non-White & 752 & 36.6 & $\begin{array}{l}1,781 \\
(86.8 \%)\end{array}$ \\
\hline Age & $12-22$ & NA & $\mathrm{SD}=1.238$ & $\begin{array}{l}2,042 \\
(99.5 \%)\end{array}$ \\
\hline
\end{tabular}


Table 2: Levene's Test of Homogeneity of Variance

\begin{tabular}{lcc}
\hline Non-dichotomous Variables & Before Sentencing & At Ocean Tides \\
\hline Delinquency (other than violence) & $2.814^{*}$ & .175 \\
Peer Relationships & $\mathrm{NA}$ & $2.847^{*}$ \\
Alcohol Use & $3.563^{*}$ & .768 \\
Marijuana Use & .759 & .480 \\
Other Drug Use & $6.166^{* *}$ & $6.883^{* *}$ \\
Academic Success & $7.047^{* *}$ & .868 \\
Socioeconomic Status & $8.481^{* *}$ & $\mathrm{NA}$ \\
\hline
\end{tabular}

$* \mathrm{p} \leq .05, * * \mathrm{p} \leq .01, * * * \mathrm{p} \leq .001$ 
Table 3: OLS and Logistic Regression Models - Before Going to Ocean Tides

\begin{tabular}{|c|c|c|c|c|c|c|c|c|c|c|c|c|c|}
\hline & \multicolumn{2}{|c|}{$\begin{array}{c}\text { Model } 1 \\
\text { Recidivism }\end{array}$} & \multicolumn{2}{|c|}{$\begin{array}{l}\text { Model } 2 \\
\text { Gang }\end{array}$} & \multicolumn{3}{|c|}{$\begin{array}{c}\text { Model } 3 \\
\text { Gun }\end{array}$} & \multicolumn{3}{|c|}{$\begin{array}{c}\text { Model } 4 \\
\text { Other Delinquency }\end{array}$} & \multicolumn{3}{|c|}{$\begin{array}{l}\text { Model } 5 \\
\text { Marijuana }\end{array}$} \\
\hline & SE B & $\mathrm{e}^{\mathrm{B}}$ & SE E & $\mathrm{e}^{\mathrm{B}}$ & $\mathrm{B}$ & SE B & $e^{B}$ & B & SE B & $\mathrm{e}^{\mathrm{B}}$ & B & SE B & $\mathrm{e}^{\mathrm{B}}$ \\
\hline UBNL & .780 & 2.181 & $-1.301 * .643$ & .274 & -.890 & .671 & .411 & 1.912 & 1.504 & .147 & -.027 & .324 & -.010 \\
\hline IL & .276 & 1.318 & $-1.591 * .704$ & .204 & -1.011 & .704 & .364 & .927 & 1.602 & .038 & .011 & .345 & .002 \\
\hline UBL & 1.073 & 2.923 & -1.051 & .350 & -.766 & .685 & .465 & 2.088 & 1.542 & .127 & .117 & .332 & .033 \\
\hline OTH & .058 & 1.060 & $-1.474 * .739$ & .229 & -.648 & .726 & .523 & .265 & 1.656 & .009 & -.292 & .356 & -.046 \\
\hline Race & .059 & 1.061 & $1.499 * * * .169$ & 4.478 & $.334 * *$ & .111 & 1.396 & $-.811 * *$ & .283 & -.076 & .109 & .061 & .048 \\
\hline Family Crime & $.414 * * * .114$ & 1.514 & -.037 & .963 & .075 & .104 & 1.078 & $1.149 * *$ & $* .267$ & .107 & $.071 *$ & .034 & .052 \\
\hline Age & $.161 * * * .045$ & 1.174 & .052 & 1.053 & -.025 & .042 & .975 & $-.365 * *$ & .107 & -.084 & $.030 *$ & .014 & .056 \\
\hline SES & .023 & 1.023 & $-.168 * * .069$ & .845 & .052 & .046 & 1.053 & -.281 & .118 & -.047 & $.039 * *$ & .015 & .068 \\
\hline Model Stats & $\begin{array}{r}\text { Wald }=202 \\
N=164\end{array}$ & $\begin{array}{l}3.624 * \\
8\end{array}$ & $\begin{array}{r}\text { Wald }=12 \\
N=16\end{array}$ & $\begin{array}{l}+2.941 \\
8\end{array}$ & Wald & $\begin{array}{l}=2250 \\
N=164\end{array}$ & $245 * *$ & & $\begin{array}{l}\mathrm{R}^{2}=.03 \\
=7.741^{*} \\
\mathrm{~N}=164\end{array}$ & & & $\begin{array}{l}\mathrm{R}^{2}=.02 \\
=4.679 \\
\mathrm{~N}=164\end{array}$ & \\
\hline
\end{tabular}

Race: 1=White; 2=Non-White. $\mathrm{e}^{\mathrm{B}}=$ Exponentiated $\mathrm{B}$. UBNL=US-Born Non-Latinx; IL=Immigrant Latinx;

$\mathrm{UBL}=\mathrm{US}$-Born Latinx; OTH=All Other Immigrants. ${ }^{*} \mathrm{p} \leq .05,{ }^{*} \mathrm{p} \leq .01,{ }^{* * *} \mathrm{p} \leq .001$ 
Table 4: OLS Regression Models - While Residing at Ocean Tides

\begin{tabular}{|c|c|c|c|c|c|c|c|c|c|c|c|c|}
\hline & \multicolumn{3}{|c|}{$\begin{array}{c}\text { Model } 9 \\
\text { Other Delinquency }\end{array}$} & \multicolumn{3}{|c|}{$\begin{array}{l}\text { Model } 10 \\
\text { Academics }\end{array}$} & \multicolumn{3}{|c|}{$\begin{array}{c}\text { Model } 11 \\
\text { Other Drugs }\end{array}$} & \multicolumn{3}{|c|}{$\begin{array}{l}\text { Model } 12 \\
\text { Alcohol }\end{array}$} \\
\hline & B & SE B & b & B & SE B & $\mathrm{b}$ & B & SE B & $\mathrm{b}$ & B & SE B & $\mathrm{b}$ \\
\hline UBNL & -2.301 & 1.873 & -.119 & .287 & .212 & .160 & -.019 & .121 & -.017 & -.009 & .213 & -.004 \\
\hline IL & -2.742 & 1.994 & -.076 & .223 & .226 & .067 & -.038 & .129 & -.017 & -.142 & .227 & -.034 \\
\hline UBL & -2.445 & 1.921 & -.100 & .354 & .218 & .157 & -.053 & .124 & -.036 & -.070 & .219 & -.028 \\
\hline OTH & -1.935 & 2.061 & -.044 & .166 & .236 & .039 & -.044 & .133 & -.017 & -.024 & .235 & -.005 \\
\hline Race & $.851 * *$ & .353 & .045 & $.106^{* *}$ & .040 & .072 & $-.052 *$ & .023 & -.055 & $-.161 * * *$ & .040 & -.086 \\
\hline Family Crime & .278 & .334 & .017 & $.080 *$ & .038 & .054 & -.039 & .022 & -.040 & $-.109 * *$ & .038 & -.058 \\
\hline Age & $-.745 * * *$ & .134 & -.115 & $.105 * * *$ & .015 & .177 & $-.026 * *$ & .009 & -.066 & $-.054 * * *$ & .015 & -.071 \\
\hline SES & -.065 & .147 & -.010 & .021 & .317 & .033 & .000 & .010 & -.001 & -.030 & .017 & -.037 \\
\hline Past Oth. Del. & $.815 * * *$ & .031 & .547 & & NA & & & NA & & & NA & \\
\hline Past Academic & & NA & & $.288 * * *$ & .035 & .205 & & NA & & & NA & \\
\hline Past OTH. Drugs & & NA & & & NA & & $.318 * * *$ & .016 & .447 & & NA & \\
\hline Past Alcohol & & NA & & & NA & & & NA & & $.530 * * *$ & .018 & .590 \\
\hline \multirow[t]{3}{*}{ Model Stats } & \multirow{2}{*}{\multicolumn{3}{|c|}{$\begin{array}{c}\mathrm{R}^{2}=.327 \\
\mathrm{~F}=88.549 * * *\end{array}$}} & \multicolumn{3}{|c|}{$\mathrm{R}^{2}=.087$} & \multicolumn{3}{|c|}{$\mathrm{R}^{2}=.213$} & \multicolumn{3}{|c|}{$\mathrm{R}^{2}=.368$} \\
\hline & & & & \multirow{2}{*}{\multicolumn{3}{|c|}{$\begin{array}{c}\mathrm{F}=15.505 * * * \\
\mathrm{~N}=1476\end{array}$}} & \multirow{2}{*}{\multicolumn{3}{|c|}{$\begin{array}{c}\mathrm{F}=49.377 * * * \\
\mathrm{~N}=1647\end{array}$}} & \multirow{2}{*}{\multicolumn{3}{|c|}{$\begin{array}{c}F=105.808 \\
N=1647\end{array}$}} \\
\hline & \multicolumn{3}{|c|}{$\mathrm{N}=1647$} & & & & & & & & & \\
\hline
\end{tabular}

Race: 1=White; 2=Non-White. $\mathrm{e}^{\mathrm{B}}=$ Exponentiated $\mathrm{B}$. UBNL=US-Born Non-Latinx; IL=Immigrant Latinx; $\mathrm{UBL}=\mathrm{US}$-Born Latinx; OTH=All Other Immigrants. ${ }^{*} \mathrm{p} \leq .05, * * \mathrm{p} \leq .01, * * * \mathrm{p} \leq .001$ 